RECOMMENDATIONS

\title{
Updated recommendations for the management of upper respiratory tract infections in South Africa
}

\begin{abstract}
A J Brink, M F Cotton, C Feldman, H Finlayson, R L Friedman, R Green, W Hendson, M H Hockman, G Maartens, S A Madhi, G Reubenson, E J Silverbauer, I L Zietsman

Dr Adrian Brink is a consultant clinical microbiologist at Ampath National Laboratory Services, Milpark Hospital, Johannesburg, South Africa; Prof. Mark Cotton is head of the Division of Paediatric Infectious Diseases, Department of Paediatrics and Child Health, Faculty of Medicine and Health Sciences, Stellenbosch University and Tygerberg Children's Hospital, Cape Town, South Africa; Prof. Charles Feldman is head of the Division of Pulmonology, Department of Internal Medicine, Charlotte Maxeke Johannesburg Academic Hospital and Faculty of Health Sciences, University of the Witwatersrand, Johannesburg; Prof. Heather Finlayson is a consultant at the Department of Paediatrics and Child Health, Faculty of Medicine and Health Sciences, Stellenbosch University and Tygerberg Children's Hospital, Cape Town; Dr Ray Friedman is an otorhinolaryngologist at Mediclinic Sandton and Netcare Linksfield Clinic, Johannesburg; Prof. Rob Green is head of the Department of Paediatrics and Child Health, University of Pretoria, South Africa; Dr Willy Hendson is a consultant in Paediatric Cardiology, Department of Paediatrics and Child Health, Rahima Moosa Mother and Child Hospital, Faculty of Health Sciences, University of the Witwatersrand; Dr Maurice Hockman is an otorhinolaryngologist at Netcare Linksfield Hospital, Johannesburg; Prof. Gary Maartens is head of the Division of Clinical Pharmacology, Department of Medicine, University of Cape Town; Prof. Shabir Madhi is Executive Director of the National Institute for Communicable Diseases and Medical Research Council: Respiratory and Meningeal Pathogens Research Unit, Faculty of Health Sciences, University of the Witwatersrand; Dr Gary Reubenson is a consultant in the Department of Paediatrics and Child Health, Faculty of Health Sciences, University of the Witwatersrand and Rahima Moosa Mother and Child Hospital, Johannesburg; Dr Eddie Silverbauer is a consultant clinical microbiologist at Ampath National Laboratory Services, Sunninghill and Waterfall hospitals, Johannesburg; and Dr Inge Zietsman is a consultant clinical microbiologist at Ampath National Laboratory Services, Sandton, and Morningside Clinic, Johannesburg. The authors constitute the Working Group of the Infectious Diseases Society of Southern Africa.
\end{abstract}

Corresponding author: A J Brink (brinka@ampath.co.za)

Background. Inappropriate use of antibiotics for non-severe upper respiratory tract infections (URTIs), most of which are viral, significantly adds to the burden of antibiotic resistance. Since the introduction of pneumococcal conjugate vaccines in South Africa in 2009, the relative frequency of the major bacterial pathogens causing acute otitis media (AOM) and acute bacterial rhinosinusitis (ABRS) has changed. Recommendations. Since URTIs are mostly viral in aetiology and bacterial AOM and ABRS frequently resolve spontaneously, these recommendations include diagnostic criteria to assist in separating viral from bacterial causes and hence select those patients who do not require antibiotics. Penicillin remains the drug of choice for tonsillopharyngitis and amoxicillin the drug of choice for both AOM and ABRS. A dose of $90 \mathrm{mg} / \mathrm{kg} / \mathrm{d}$ is recommended for children, which should be effective for pneumococci with high-level penicillin resistance and will also cover most infections with Haemophilus influenzae. Amoxicillin-clavulanate (in high-dose amoxicillin formulations available for both children and adults) should be considered the initial treatment of choice in patients with recent antibiotic therapy with amoxicillin (previous 30 days) and with resistant $H$. influenzae infections pending the results of studies of local epidemiology ( $\beta$-lactamase production $\geq 15 \%)$. The macrolide/azalide class of antibiotics is not recommended routinely for URTIs and is reserved for $\beta$-lactam-allergic patients. Conclusion. These recommendations should facilitate rational antibiotic prescribing for URTIs as a component of antibiotic stewardship. They will require updating when new information becomes available, particularly from randomised controlled trials and surveillance studies of local aetiology and antibiotic susceptibility patterns.

S Afr Med J 2015;105(5):345-352. DOI:10.7196/SAMJ.8716

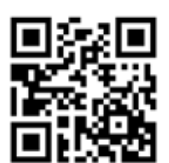

\section{Background}

The initial and subsequent revised upper respiratory tract infection (URTI) guideline for South Africa (SA) was published in 2004 and in 2008 in the SAMJ and the South African Journal of Epidemiology and Infection, respectively. ${ }^{[1,2]}$ In 2014, new multidisciplinary experts were invited to join the original working group of the Infectious Diseases Society of Southern Africa to prepare the current recommendations. The methods used are similar to those described before, and the process was done electronically, including review from international experts.

There is a worldwide increase in antibiotic resistance, and studies suggest that this is contributed to by inappropriate use of antibiotics, particularly for URTIs. ${ }^{[3]}$ Viral infections cause the majority of URTIs. All clinicians should know the natural history of the 'common cold' so that a deviation from normal can be managed effectively. Most important is an appreciation that clear nasal secretions frequently become purulent without signifying secondary bacterial disease, and that coughing is a normal accompaniment (Fig. 1).

The organisms responsible for most bacterial URTIs are similar in all age groups. Streptococcus pneumoniae (the pneumococcus) was previously the most common bacterial cause of acute otitis media (AOM) and sinusitis. Haemophilius influenzae has replaced pneumococci as the most frequently isolated pathogen following routine vaccination of children with pneumococcal conjugate vaccines (PCVs) (PCV-7 was introduced in SA in 2009 and replaced by PCV-13 in 2011). ${ }^{[4]}$

Systematic reviews suggest that in high-income countries the benefit of antibiotics for acute pharyngotonsillitis, $\mathrm{AOM}$ and acute bacterial rhinosinusitis (ABRS) is extremely limited. ${ }^{[5-7]}$ For example, 13 (95\% confidence interval (CI) 9 - 22) adults with ABRS require antibiotics 
to benefit one. ${ }^{[5]}$ However, there are few data from low- and middle-income countries, where rheumatic fever and suppurative complications such as mastoiditis are more common. Through simple recommendations of antibiotics with a relatively narrow spectrum, patients ought to be well managed, serious complications avoided and the propensity to select for resistance minimised. The most frequently recommended initial antibiotics of choice for URTIs therefore remain penicillin and amoxicillin.

The recommendations for duration of therapy differ: ABRS and acute pharyngotonsillitis should be treated for 5 and 10 days, respectively, and AOM for 5 or 7 days. Recent evidence suggests that a shorter duration of antibiotic treatment is associated with less emergence of resistant pathogens. ${ }^{[8]}$ Duration will always depend on clinical response, and in some patients antibiotic duration may need to be shortened or prolonged. However, 10 days of oral penicillin is required to eradicate group A $\beta$-haemolytic streptococci (GABHS) (S. pyogenes) in patients with pharyngotonsillitis.

The recommendations for frequency of administration vary according to the site of infection and the pharmacokinetic/ pharmacodynamic (PK/PD) profiles of the drugs used. In AOM a twice-daily dose of amoxicillin has the same clinical efficacy as amoxicillin administered three times a day. For optimal clinical success, the antibiotic dosage must be tailored to the individual. A common cause of treatment failure and antibiotic resistance is suboptimal dosing. For example, in AOM $5 \mathrm{~mL}$ is erroneously prescribed as a standard dose for a child weighing $5-15 \mathrm{~kg}$, instead of individualising doses by body mass. Dosages in this guideline include both the registered standard doses and higher doses,

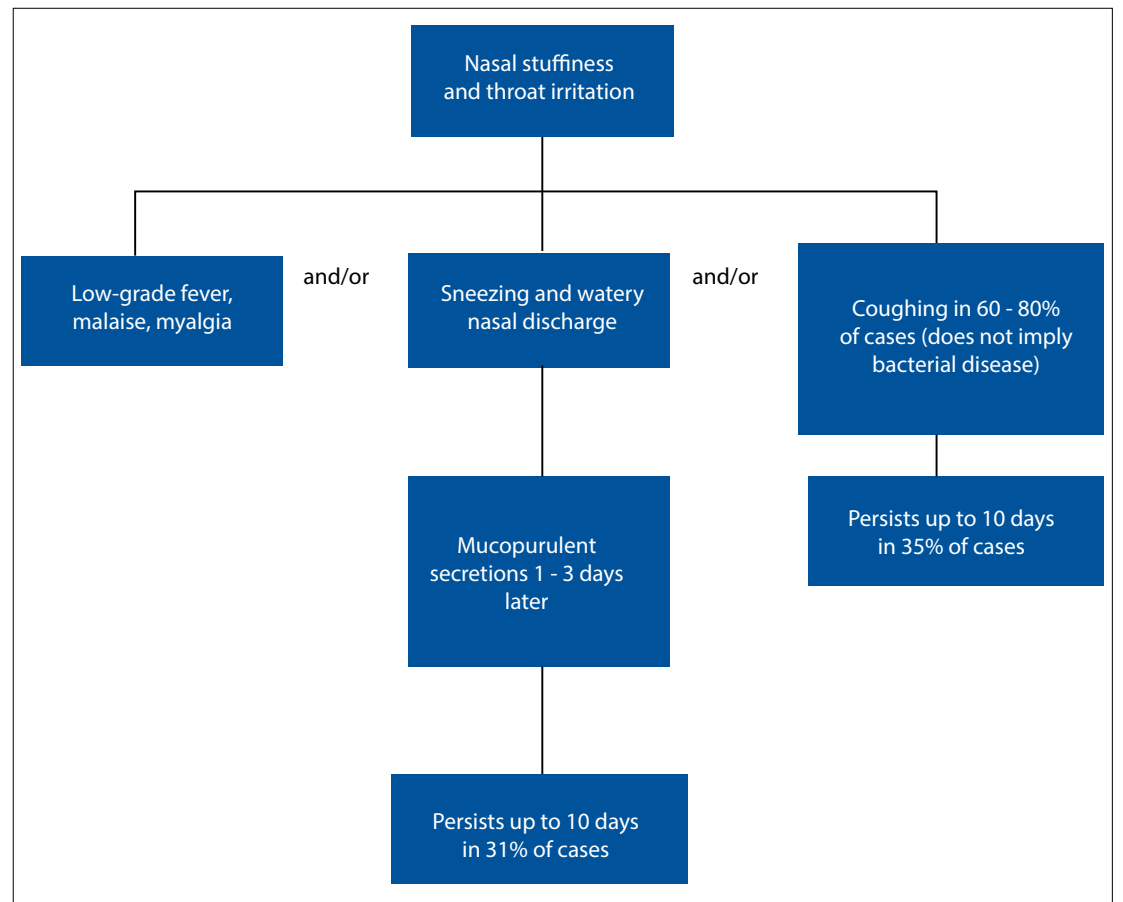

Fig. 1. Natural history of the common cold.

which are recommended where high-level antibiotic resistance is reported (see Tables 6 and 7). All paediatric doses are given as $\mathrm{mg} /$ $\mathrm{kg}$ per dose, followed by frequency of daily administration. Recommendations have been made based on surveillance of appropriate pathogens and relevant publications. ${ }^{[4,9,10]}$

For S. pneumoniae, an important pathogen causing $\mathrm{AOM}$ and $\mathrm{ABRS}$, resistance to $\beta$-lactam antibiotics can be overcome by increasing antibiotic dosage. For example, a higher dose of amoxicillin of $90 \mathrm{mg} /$ $\mathrm{kg} / \mathrm{d}$ is recommended for AOM and ABRS. Amoxicillin should be effective for $H$. influenzae not producing $\beta$-lactamases. Because of concerns of high-level macrolide resistance among isolates of $S$. pneumoniae in some areas of practice in SA, this class is reserved for patients with severe $\beta$-lactam antibiotic allergy. Furthermore, in terms of PK/PDs and clinical studies that include microbiological efficacy results, all macrolides, including azithromycin, are ineffective in eradicating $H$. influenzae.

Recommendations for initial antibiotics of choice as well as alternative choices of antibiotics are given. The first-line antibiotics penicillin or amoxicillin remain the agents of choice. The indications for alternative antibiotics may include the following:

- Allergy or intolerance to first-line agents

- Recent prior use of first-line agents

- Complicated and/or severe initial presentation

- High-risk cases likely or known to be infected with highly resistant organisms

- Failed initial therapy.

These recommendations are based on best practice, taking into account unique local circumstances.

\section{Acute \\ pharyngotonsillitis}

Acute pharyngotonsillitis is an inflammatory condition of the pharyngeal wall, often divided into pharyngitis and tonsillitis. Respiratory viruses, including adenoviruses, Coxsackie

\section{Table 1. Diagnostic and treatment criteria for acute pharyngotonsillitis}

1. Symptoms suggestive of acute pharyngitis/tonsillitis are sore throat, fever, difficulty in swallowing, halitosis, etc. However, clinicians' ability to differentiate GABHS pharyngitis from other causes is limited. Therefore:

2. The prescence of coryza, cough, conjunctivitis, hoarseness, anterior stomatitis, discrete ulcerative lesions or diarrhoea makes GABHS unlikely, and no antibiotics are recommended.

3. If none of the above symptoms is present, two alternative approaches are recommended:

- A throat swab for GABHS: if positive, prescribe antibiotics*

- No throat swab for GABHS: empiric antibiotic therapy for patients aged $3-21$ years ${ }^{\dagger}$

4. Tender anterior cervical lymphadenopathy, pharyngeal erythema or exudate increases the likelihood of GABHS pharyngitis.

${ }^{*}$ A delay in antibiotic prescription pending availability of culture results does not reduce efficacy in ARF prevention.

Throat swabs for GABHS confirmation may be not be feasible in many SA settings owing to increased direct and indirect financial expenditure and additional healthcare visits. 
Table 2. Penicillin recommendations for acute pharyngotonsillitis

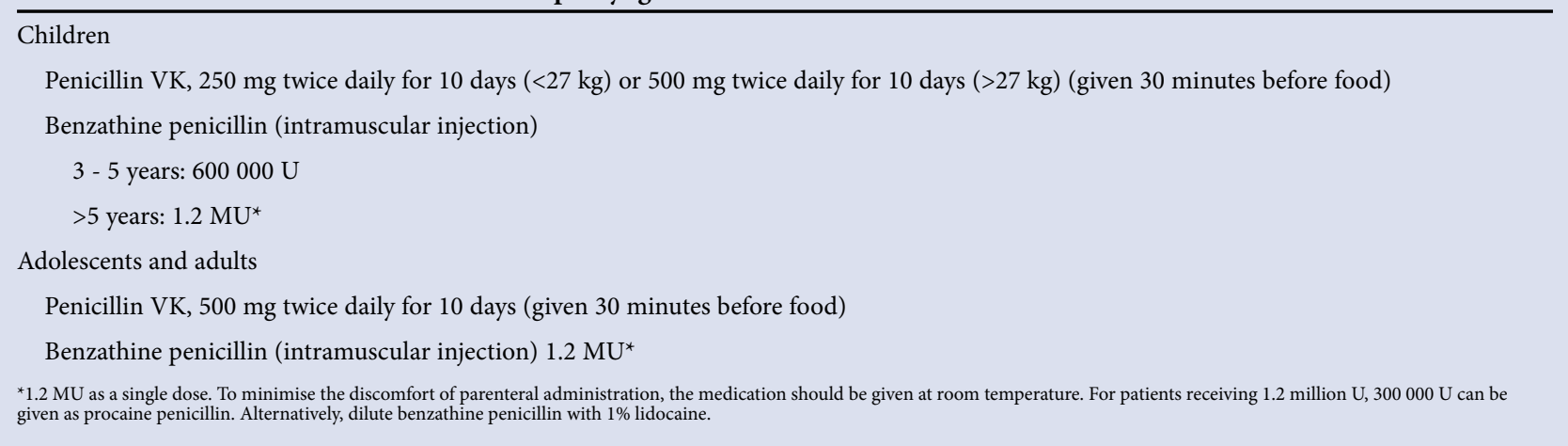

A virus, influenza virus, parainfluenza virus and Epstein-Barr virus (EBV), are the major cause of pharyngitis. Bacteria, especially GABHS (S. pyogenes), account for $5-30 \%$ of cases. $^{[11]}$ Correctly performed throat culture has a sensitivity of 90 - 95\% for detecting GABHS. Non-infectious causes of pharyngitis include allergy and exposure to irritating substances. Most cases of viral and bacterial acute pharyngitis are self-limiting, including those caused by GABHS, so the primary reason for considering antibiotic therapy is to prevent acute rheumatic fever (ARF). Of note, as approximately two-thirds of patients with ARF have no preceding sore throat, antibiotics have only a limited ability to reduce the incidence of ARF. Patients with rheumatic heart disease or prior episode(s) of ARF should receive secondary penicillin prophylaxis, but require antibiotic therapy for acute pharyngitis (suggestive of GABHS) initially (Table 1).

\subsection{Antibiotic recommendations for streptococcal pharyngotonsillitis}

The treatment of choice is penicillin (Table 2).

\subsubsection{Penicillin}

Penicillin reduces the risk of ARF and provides some symptom relief in GABHS. ${ }^{[12]}$ A single dose of intramuscular benzathine penicillin is adequate, but oral therapy may be preferred if compliance is considered likely. The mixture of benzathine penicillin and procaine penicillin gives a less painful injection. ${ }^{[13]}$ Alternatively, a dilution of benzathine penicillin with $1 \%$ lidocaine has been shown to be well tolerated. ${ }^{[14]}$ When given by mouth, penicillin can be given twice or three times daily instead of four times a day. Penicillin should be given 30 minutes before a meal, as food reduces its absorption. A 10-day course is recommended. An important point in favour of continued use of penicillin is the lack of resistance by GABHS, as opposed to the use of erythromycin and other macrolides, where widespread use promotes resistance. ${ }^{[15,16]}$ An additional advantage of penicillin is its

Table 3. Amoxicillin recommendations for acute pharyngotonsillitis

Children*

Amoxicillin $50 \mathrm{mg} / \mathrm{kg} / \mathrm{d}$ once daily (maximum $1000 \mathrm{mg}$ ) for 10 days

Adolescents and adults*

Amoxicillin 500 - $1000 \mathrm{mg}$ twice daily (alternatively, $50 \mathrm{mg} / \mathrm{kg} / \mathrm{d}$ once daily (maximum

$3000 \mathrm{mg})$ ) for 10 days

${ }^{\star}$ Dose to the closest increment of $125 \mathrm{mg}$.

Table 4. Recommendations for $\beta$-lactam allergy in acute pharyngotonsillitis

Children

Azithromycin 10 - $20 \mathrm{mg} / \mathrm{kg} / \mathrm{d}$ once daily for 5 days

Clarithromycin $15 \mathrm{mg} / \mathrm{kg} / \mathrm{d}$, divided into two doses, for 10 days

Adolescents and adults

Azithromycin $500 \mathrm{mg}$ once daily for 3 days

Clarithromycin $500 \mathrm{mg}$ twice daily or $500 \mathrm{mg}$ modified-release once daily for 10 days

narrow spectrum of activity, which reduces the risk of selection of resistance.

\subsubsection{Amoxicillin}

Amoxicillin is an alternative to penicillin VK and has the advantage of no food restrictions (Table 3). However, a rash can occur when pharyngotonsillitis is caused by EBV infection, which can lead to an erroneous diagnosis of penicillin allergy or, rarely, a severe skin reaction. However, recent evidence suggests that this rash is much less common with amoxicillin $(\sim 30 \%$ risk in confirmed $\mathrm{EBV}$ infection) than with ampicillin. Several trials have demonstrated non-inferiority of oncedaily amoxicillin to twice-daily amoxicillin or penicillin $V^{[17,18]}$ Once-daily regimens may improve patient adherence.

\subsubsection{Alternative antibiotic choices \\ 2.1.3.1 Short-course therapy (5 days)}

Short-course therapy with several antibiotics including the cephalosporins (cefuroxime, cefprozil, cefpodoxime) has been shown to be non-inferior to a 10 -day course of penicillin
VK. ${ }^{[6]}$ However, whether shorter courses provided similar reduction in ARF is unknown. Furthermore, cephalosporins are broaderspectrum agents than penicillin/amoxicillin and have a greater propensity to select for resistance. A 10-day course of penicillin or amoxicillin is therefore recommended.

\subsubsection{Antibiotics for $\beta$-lactam allergy}

Macrolide/azalide resistance in GABHS is a major concern, and use of these agents should therefore be restricted to penicillin-allergic patients (Table 4).

\subsection{Symptom relief}

The mainstay of the management of acute pharyngitis is symptomatic. This includes adequate analgesia and antipyretics for the relief of fever-related symptoms (generally paracetamol or ibuprofen), and sufficient hydration.

\section{Acute otitis media}

AOM is a common childhood illness - $75 \%$ of children have at least one episode by 3 
years of age. However, AOM is often misdiagnosed (Table 5). The main bacterial causes of AOM are S. pneumoniae, non-typeable $H$. influenzae, and Moraxella catarrhalis. Since the introduction in RSA of PCV-7 in 2009, followed by PCV-13 in 2011, the relative frequency of these three major middle ear pathogens has changed. H. influenzae has replaced S. pneumoniae as the most frequently isolated middle ear pathogen. ${ }^{[4]}$ Up to $12.2 \%$ (range $9.5-15.5 \%$ ) of $H$. influenzae isolated from respiratory tract infections in SA produce $\beta$-lactamase, and this is even more frequent if the child was recently on antibiotics, resulting in resistance to penicillins. ${ }^{[10]}$ As otitis media may be part of neonatal sepsis, any neonate with $\mathrm{AOM}$ and fever requires evaluation for sepsis. Causative organisms in neonatal AOM include coliforms, group B $\beta$-haemolytic streptococci and Staphylococcus aureus.

\subsection{Treatment of AOM}

As AOM is often viral in aetiology, with even bacterial AOM frequently resolving spontaneously, antibiotics may be deferred for 48 hours while symptomatic therapy is administered, except for AOM cases associated with a bulging tympanum and a temperature of $>38^{\circ} \mathrm{C}$, where, although this is controversial, immediate treatment is recommended. In addition, if symptoms persist or worsen, antibiotics should be started. A useful approach is to provide a prescription to be filled only if no improvement by 48 hours; this approach is reasonable where good follow-up is possible in children $\geq 2$ years of age. However, in patients with limited access to healthcare and because of the risks of a serious infection with S. pneumoniae and/ or $H$. influenzae, we recommend that treatment commence from the first visit, provided the AOM is correctly diagnosed.

Antibiotics should be considered especially in the following cases:

- Recurrent AOM

- Immunocompromised patients

- Neonates

- Structural ENT or immunological abnormalities

- Fever (temperature $>38^{\circ} \mathrm{C}$ ) or pain $>48$ hours

- Day-care attendees or siblings of children attending day-care centres.

Risk factors for resistant $S$. pneumoniae infections include age $(\leq 2$ years), attendance at day-care centres or siblings of children attending day-care centres, not vaccinated with PCVs, prior AOM within the past
6 months, and antibiotic treatment within the past 3 months. These influence the choice and dosage of antibiotics. Risk factors for resistant $H$. influenzae infections have not been elucidated, but a recent course of antibiotics that are not resistant to $\beta$-lactamases (i.e. amoxicillin) increases the risk for $\beta$-lactamase-producing $H$. influenzae.

Paracetamol (10 - $15 \mathrm{mg} / \mathrm{kg} 4$ - 6-hourly) or ibuprofen (5 - $10 \mathrm{mg} /$ kg 8-hourly) can be given for symptom relief (avoid under- and overdosing). Although decongestants are widely prescribed for rhinitis, their use in AOM is controversial and generally discouraged. If used, topical nasal application for a maximum of 3 days is preferable.

\subsection{AOM with tympanostomy tubes (AOMT)}

$\mathrm{AOM}$ with otorrhoea in patients with tympanostomy tubes is considered a separate clinical entity, since in a child with glue ear a biofilm disease is present, so acute otitis in this situation represents acute exacerbation of a chronic process. This is a common problem, and culture of otorrhoea fluid will often show significant growth of bacteria such as Pseudomonas aeruginosa and $S$. aureus in addition to the usual pathogens. As $\beta$-lactams do not cover the entire spectrum of organisms cultured, a topical otological formulation of ciprofloxacin is an efficacious therapeutic option for managing AOMT, avoiding oral treatment. ${ }^{[19]}$ The advantages of topical antibiotics administered correctly, rather than systemic antibiotics, include significantly higher tissue levels, substantially reduced adverse effects and, perhaps most importantly, considerably less likelihood of antimicrobial resistance.

\subsection{Antibiotic choices for AOM}

The initial antibiotic treatment of choice, except in neonates, is amoxicillin. Amoxicillin-clavulanate is recommended as the initial antibiotic treatment of choice for suspected resistant $H$. influenzae, particularly if there is history of prior antibiotic use (preceding 30 days) with an antibiotic that was not $\beta$-lactamase stable (e.g amoxicillin), or if local data show a high proportion $(\geq 15 \%)$ of resistance to amoxicillin (mediated by $\beta$-lactamase production).

\subsubsection{Amoxicillin}

The recommended dosage of amoxicillin is $80-90 \mathrm{mg} / \mathrm{kg} / \mathrm{d}$. This higher dose is associated with a better eradication of $H$. influenzae and

\section{Table 5. Diagnostic criteria for AOM}

1. AOM is defined as an acute upper respiratory tract infection, affecting one or both ears (often associated with infection in the rest of the upper respiratory tract), presenting with:

- Otalgia (holding, tugging, rubbing of the ear in a non-verbal child)

- Hearing loss

- Pyrexia, with nausea and dizziness that may develop concurrently

2. Symptom presentation varies with age. However, as typical symptoms overlap with other conditions, a clinical history alone is not sufficient to predict whether AOM is present. The middle ear mucositis develops an effusion, in this case suppuration, as evidenced by a tympanic membrane that may become:

- Red

- Oedematous

- Immobile

- Bulging

3. Hence, to confirm the diagnosis, middle ear effusion and inflammation of the eardrum have to be identified by visualisation of the tympanic membrane (TM). Signs of these are fullness, bulging, cloudiness and redness of the TM. Pneumotoscopy and tympanometry are very useful in determining the presence of a middle ear effusion. Other causes of a 'red' TM include crying, otitis externa, myringitis and barotrauma. AOM is as a consequence frequently misdiagnosed. Similarly, over-diagnosis is common. 
overcomes high-level penicillin-resistant pneumococci, particularly prevalent for:

- Age $\leq 2$ years

- Day-care attendees or siblings of children attending day-care centres

- AOM in previous 6 months

- Antibiotic administration during 30 days preceding the AOM episode.

\subsubsection{Amoxicillin-clavulanate}

The addition of a $\beta$-lactamase inhibitor (clavulanate) extends the spectrum of amoxicillin to include $\beta$-lactamase-producing $H$. influenzae and M. catarrhalis. A high-dose amoxicillin-clavulanate preparation $(90 \mathrm{mg} /$ $\mathrm{kg}$ amoxicillin and a constant amount of clavulanate of $6.4 \mathrm{mg} / \mathrm{kg}$ ) is available in a paediatric formulation. This gives dosages adequate to also eradicate S. pneumoniae that are susceptible to or have high-level resistance to penicillin. This formulation may not be available in all SA sectors. In order to achieve the higher dose, additional amoxicillin can be added to standard-dose amoxicillin-clavulanate formulations to achieve an amoxicillin concentration of $80-90 \mathrm{mg} / \mathrm{kg}$, which is better than simply doubling the doses of standard preparations (additional clavulanate is not required, and maintaining the clavulanate dose lowers the risk of gastrointestinal side-effects). Similarly, if the high-dose amoxicillinclavulanate formulation ( $2000 \mathrm{mg}$ amoxicillin- $125 \mathrm{mg}$ clavulanate) that is registered for adults is not available, additional amoxicillin $(1000 \mathrm{mg})$ can be added to a standard-dose amoxicillin-clavulanate formulation (e.g. $875 \mathrm{mg}$ amoxicillin-125 mg clavulanate).

\subsubsection{Oral cephalosporins}

Cefuroxime axetil and cefpodoxime are the only oral cephalosporins that give middle ear fluid (MEF) levels sufficiently above the minimum inhibitory concentration (MIC) for both penicillinsensitive and some intermediate-resistant $S$. pneumoniae and for $H$. influenzae. ${ }^{[20]}$ Considering the high prevalence of $\beta$-lactam resistance in many areas of SA, these cephalosporins should be prescribed at the higher dosages detailed below if used to treat AOM. Based upon PK/PD findings and clinical trials of AOM, cefuroxime axetil and cefpodoxime are expected to fail in many cases of penicillin-intermediate and resistant pneumococcal strains, while cefprozil ( $15 \mathrm{mg} / \mathrm{kg}$ twice daily) should not be used empirically in this setting, as it is only effective against penicillin-susceptible pneumococci. ${ }^{[21]}$ Cefaclor, cefixime and loracarbef are less active in vitro against $S$. pneumoniae and are not recommended.

\subsubsection{Parenteral cephalosporins}

The MEF concentration of ceftriaxone exceeds the MICs for AOM pathogens for $>50$ hours after a single $50 \mathrm{mg} / \mathrm{kg}$ intramuscular injection. However, a 3-day regimen is clinically superior, particularly in non-responsive AOM caused by penicillin-resistant S. pneumoniae. ${ }^{[22]}$ Ceftriaxone use should be reserved for failure of high-dose amoxicillin-clavulanate, for severe presentations, or if oral administration is unreliable. These scenarios may require specialist consultation.

\subsubsection{Macrolides/azalides}

The erm gene mutation causing high-level resistance to macrolides, which cannot be overcome by dose increase, has been identified in the majority of erythromycin-resistant $S$. pneumoniae strains in some sectors in SA. ${ }^{[23]}$ Macrolides are therefore not recommended for routine empirical antibiotic therapy of $S$. pneumoniae infections and are reserved for type $1 \beta$-lactam hypersensitivity. Furthermore, in terms of PK/PDs

\section{Table 6. Antibiotic recommendations for children with AOM or ABRS}

\begin{tabular}{|c|c|c|c|}
\hline \multicolumn{2}{|l|}{ Initial antibiotic treatment } & \multicolumn{2}{|c|}{ Failure of initial antibiotic treatment after $48-72$ hours } \\
\hline Recommended drug of choice & Alternative treatment if penicillin & Recommended drug of choice & Alternative treatment \\
\hline Amoxicillin $(80-90$ mg/kg/d & allergy (non-type 1) & Amoxicillin-clavulanate* & Ceftriaxone $^{\S}(50 \mathrm{mg} / \mathrm{kg} / \mathrm{d} \mathrm{IM}$ \\
\hline divided into 2 doses) & Azithromycin $(10 \mathrm{mg} / \mathrm{kg}$ once & (90 mg/kg/d amoxicillin-6.4 & or IV once daily) for 3 days \\
\hline$<2$ years 7 days & daily) for 3 days & $\mathrm{mg} / \mathrm{kg} / \mathrm{d}$ clavulanate divided & Clindamycin $(90-150$ \\
\hline$>2$ years 5 days & Clarithromycin (15 - $30 \mathrm{mg} /$ & into 2 doses) & $\mathrm{mg} / \mathrm{kg} / \mathrm{d}$ divided into 3 \\
\hline OR & $\mathrm{kg} / \mathrm{d}$ divided into 2 doses) for & $<2$ years $7-10$ days & doses) with or without a \\
\hline Amoxicillin-clavulanate $^{\star}(90$ & 5 days & $>2$ years 5 - 7 days & second- or third-generation \\
\hline mg/kg/d amoxicillin-6.4 mg/ & Erythromycin estolate $(40 \mathrm{mg} /$ & OR & cephalosporin ${ }^{\dagger}$ for 5 - 7 days \\
\hline $\mathrm{kg} / \mathrm{d}$ clavulanate divided into & $\mathrm{kg} / \mathrm{d}$ divided into 4 doses) for & Ceftriaxone $^{\S}(50 \mathrm{mg} / \mathrm{kg} / \mathrm{d}$ IM & \\
\hline 2 doses) & 5 days & or IV once daily) for 3 days & Failure of antibiotic therapy, \\
\hline Cefuroxime $^{\dagger}(30 \mathrm{mg} / \mathrm{kg} / \mathrm{d}$ & & & severe toxicity and/or \\
\hline divided into 2 doses) & Alternative treatment if penicillin & & progression beyond the \\
\hline Cefpodoxime $^{\dagger}(16 \mathrm{mg} / \mathrm{kg} / \mathrm{d}$ & allergy (type 1) & & middle ear \\
\hline divided into 2 doses) & Levofloxacin ${ }^{\ddagger}(20 \mathrm{mg} / \mathrm{kg} / \mathrm{d}$ & & Refer for further evaluation \\
\hline$<2$ years 7 days & once daily or divided into 2 & & and management \\
\hline$>2$ years 5 days & doses) for 5 days & & \\
\hline \multicolumn{4}{|c|}{$\begin{array}{l}\text { IM = intramuscular; IV }=\text { intravenous. } \\
{ }^{*} \text { If the high-dose amoxicillin-clavulanate formulation }(90 \mathrm{mg} / \mathrm{kg} / \mathrm{d} \text { amoxicillin- } 6.4 \mathrm{mg} / \mathrm{kg} / \mathrm{d} \text { clavulanate) is not available, standard-dose amoxicillin-clavulanate (e.g. } 45 \mathrm{mg} / \mathrm{kg} / \mathrm{d} \mathrm{amoxicillin}-6.4 \mathrm{mg} / \\
\mathrm{kg} / \mathrm{d} \text { clavulanate divided into } 2 \text { doses) plus additional amoxicillin }(40-45 \mathrm{mg} / \mathrm{kg} / \mathrm{d} \text { divided into } 2 \text { doses) can be used. Amoxicillin-clavulanate may be considered first-line therapy in patients with: }\end{array}$} \\
\hline $\begin{array}{l}\text { - Recent amoxicillin therapy (previous } 30 \\
\text { - Concurrent conjunctivitis } \\
\text { - Suspected resistant H. influenzae pendin } \\
\text { - Additional risk factors for AOM caused }\end{array}$ & $\begin{array}{l}\text { rbital oedema in cases of ABRS } \\
\text { ocal epidemiology ( } \% \text {-lactamase production) } \\
\beta \text {-lactamase-producing pathogens may include i }\end{array}$ & compromised patients and/or neonates. & ( \\
\hline \multicolumn{4}{|c|}{$\begin{array}{l}\text { Tephalosporins are alternative } \beta \text {-lactamase-stable agents available for the treatment of AOM. The higher dosages of cephalosporins recommended would cover for most pneumococcal } \\
\text { isolates of intermediate resistance to penicillin, but not necessarily for pneumococcal isolates with high-level resistance. The particular choice of cephalosporins would depend on physician } \\
\text { or patient preference, availability and cost. The cephalosporins (second or third generation) may also be used as alternative treatment for non-type } 1 \beta \text {-lactam allergies (refer to section } 5 \text {, } \\
\beta \text {-lactam allergy). }\end{array}$} \\
\hline
\end{tabular}


Table 7. Antibiotic recommendations for adults with ABRS or AOM

\begin{tabular}{|c|c|c|c|}
\hline \multicolumn{2}{|l|}{ Initial antibiotic treatment } & \multicolumn{2}{|c|}{ Failure of initial antibiotic treatment after $48-72$ hours } \\
\hline $\begin{array}{l}\text { ecommended drug of choice } \\
\text { Amoxicillin ( } 1 \mathrm{~g} \text { 8-hourly) for } \\
5 \text { days } \\
\text { OR } \\
\text { Amoxicillin-clavulanate } \\
\text { (2000 mg amoxicillin-125 mg } \\
\text { clavulanate } 12 \text {-hourly) for } \\
5 \text { days } \\
\text { Cefuroxime }{ }^{\dagger} \text { ( } 1000 \mathrm{mg} \\
12 \text {-hourly) for } 5 \text { days } \\
\text { Cefpodoxime }{ }^{\dagger}(400 \mathrm{mg} \\
\text { 12-hourly) for } 5 \text { days }\end{array}$ & $\begin{array}{l}\text { Alternative treatment if penicillin } \\
\text { allergy } \\
\text { Telithromycin ( } 800 \mathrm{mg} \text { once } \\
\text { daily) for } 5 \text { days } \\
\text { Gemifloxacin ( } 320 \mathrm{mg} \text { once } \\
\text { daily) for } 5 \text { days } \\
\text { Levofloxacin ( } 500 \mathrm{mg} \\
\text { 12-hourly or } 750 \mathrm{mg} \text { once } \\
\text { daily) for } 5 \text { days } \\
\text { Moxifloxacin ( } 400 \mathrm{mg} \text { once } \\
\text { daily) for } 5 \text { days }\end{array}$ & $\begin{array}{l}\text { ecommended drug of choice } \\
\text { Amoxicillin-clavulanate* } \\
\text { (2 } 000 \mathrm{mg} \text { amoxicillin- } 125 \\
\text { mg clavulanate } 12 \text {-hourly) for } \\
5 \text { - } 7 \text { days } \\
\text { Telithromycin ( } 800 \mathrm{mg} \text { once } \\
\text { daily) for } 5 \text { - } 7 \text { days } \\
\text { Gemifloxacin ( } 320 \mathrm{mg} \text { once } \\
\text { daily) for } 5 \text { - } 7 \text { days } \\
\text { Levofloxacin ( } 500 \mathrm{mg} \\
\text { 12-hourly or } 750 \mathrm{mg} \text { once } \\
\text { daily) for } 5 \text { - } 7 \text { days } \\
\text { Moxifloxacin ( } 400 \mathrm{mg} \text { once } \\
\text { daily) for } 5 \text { - } 7 \text { days } \\
\text { Clindamycin }{ }^{\ddagger} \text { ( } 450 \mathrm{mg} \\
\text { 8-hourly) for } 5 \text { - } 7 \text { days } \\
\text { Ceftriaxone for } 3 \text { days (IV/IM) }\end{array}$ & $\begin{array}{l}\text { Refer to otorhinolaryngologist } \\
\text { for further evaluation and } \\
\text { management }\end{array}$ \\
\hline \multicolumn{4}{|c|}{$\begin{array}{l}\text { IV = intravenous; IM = intramuscular. } \\
\text { *If the high-dose amoxicillin-clavulanate formulation ( } 2000 \mathrm{mg} \text { amoxicillin- } 125 \mathrm{mg} \text { clavulanate) is not available, the standard-dose amoxicillin-clavulanate formulation ( } 875 \mathrm{mg} \text { amoxicillin-125 mg } \\
\text { clavulanate } 12 \text {-hourly) plus additional amoxicillin ( } 1000 \mathrm{mg} 12 \text {-hourly) can be used. Amoxicillin-clavulanate may be considered first-line therapy in patients with: } \\
\text { - Recent amoxicillin therapy (previous } 30 \text { days) } \\
\text { - Recurrent ABRS } \\
\text { - Suspected resistant } H \text {. influenzae pending local epidemiology (\% } \beta \text {-lactamase production) } \\
\text { Additional risk factors for ABRS caused by } \beta \text {-lactamase-producing pathogens may include immunocompromised patients, including pregnant patients and diabetics. } \\
\text { the higher dosages of cephalosporins recommended would cover for most pneumococcal isolates of intermediate resistance to penicillin, but not necessarily for pneumococcal isolates with high- } \\
\text { level resistance. The particular choice of cephalosporins would depend on physician or patient preference, availability and cost. The cephalosporins (second or third generation) may also be used as } \\
\text { alternative treatment for non-type } 1 \beta \text {-lactam allergies (refer to section } 5 \text {, } \beta \text {-lactam allergy). } \\
\text { fClindamycin use is restricted to confirmed pneumococcal ABRS unresponsive to } \beta \text {-lactam antibiotics or as additional therapy to provide for anaerobic and } S . \text { aureus cover, despite the lack of } \\
\text { clinical evidence at this time of the safety or efficacy of combination therapy for ABRS. } \\
\text { 'Ceftriaxone or the respiratory fluoroquinolones may also be used as first-line therapy in complicated initial presentations, e.g. periorbital oedema, preferably in consultation with an } \\
\text { otorhinolaryngologist. }\end{array}$} \\
\hline
\end{tabular}

and clinical studies with microbiological results, all macrolides, including azithromycin, are not effective in eradication of $H$. influenzae.

\subsubsection{Trimethoprim-sulfamethoxazole (TMP-SMX)}

The high rate of resistance of S. pneumoniae and H. influenzae in SA precludes using TMP-SMX. High bacteriological failure rates have been noted in double-tap studies. ${ }^{[24]}$

\subsection{Duration of therapy for AOM}

Most antibiotics are clinically effective for uncomplicated AOM in regimens of 5 days, since eradication of organisms takes place within 72 hours. ${ }^{[25]}$ However, therapy beyond 72 hours is required for adequate eradication of potentially pathogenic bacteria colonising the nasopharynx, which otherwise predispose to relapses of AOM. Further studies are needed to determine the optimal duration of therapy in children $<2$ years of age or with non-responsive AOM. ${ }^{[20,26]}$ Until then, therapy for 7 days is recommended for AOM in the following groups:

- Age $\leq 2$ years

- Recurrent or chronic AOM

- Complicated AOM.

\subsection{Failure to respond to antibiotics in AOM}

For clinical failure (e.g. persistent fever) after $48-72$ hours of appropriate, compliant initial antibiotic therapy, consider referral to an otorhinolaryngologist for tympanocentesis and MEF culture. This is relevant in areas with a high prevalence of antibiotic-resistant $S$. pneumoniae, as are the majority of major urban centres in SA.

\subsection{Antibiotic recommendations for AOM 3.6.1 Children}

Antibiotic recommendations for children are set out in Table 6 .

\subsubsection{Adults}

For adults, AOM and ABRS have identical treatment (Table 7).

\subsection{Antibiotic recommendations for AOMT}

The recommended topical formulation contains ciprofloxacin $0.3 \%$ and dexamethasone $0.1 \%$ in an otic suspension, applied four drops twice daily for 7 days. The technique of application of the drops is essential to the success of this treatment regimen. Aural toilet by suctioning must be performed before instilling the drops into the external auditory canal, and must be followed by tragal pressure to push the drops through the tympanostomy tubes into the middle ear. A disposable nasal aspirator may be used for suctioning at home.

\section{Acute bacterial rhinosinusitis}

ABRS is usually preceded by a viral URTI. Allergy, trauma, dental infection or other factors leading to inflammation of the nose and paranasal sinuses may also predispose individuals to ABRS. The most common bacterial isolates from the maxillary sinuses in ABRS are similar to AOM, namely $S$. pneumoniae, $H$. influenzae and $M$. catarrhalis. However, both the prevalence of $H$. influenzae and the proportion of $\beta$-lactamase-producing $H$. influenzae have markedly increased in URTIs, including ABRS in children and adults, since the widespread use of PCV. The diagnostic criteria for ABRS are set out in Table 8.

Antibiotic therapy must be capable of eradicating S. pneumoniae, which, as in AOM, causes most of the serious sequelae. Other streptococci, anaerobic bacteria and $S$. aureus occur in a small percentage of cases. Chlamydophila pneumoniae and other 'atypical' pathogens should be considered in patients with chronic sinusitis. Fungi are rarely associated with sinusitis and may be seen in allergic sinusitis and immunocompromised hosts. However, their clinical 


\section{Table 8. Diagnostic criteria for ABRS}

1. Rhinosinusitis (all-cause including viral) is diagnosed when the following signs and symptoms are present:

One of either:

- Anterior or postnasal discharge

- Nasal obstruction

With or without:

- Facial pain/pressure

- Change in sense of smell

2. Acute bacterial rhinosinusitis requiring antibiotics is only diagnosed if:

Symptoms $>10$ days and $<3$ months

Severe lasting purulence or fever

Worsening of above symptoms ('second sickening') occurs in $<10$ days

3. Acute viral rhinosinusitis (often associated with the common cold) is diagnosed if:

Symptoms $<10$ days

Non-severe symptoms

No 'second sickening' occurred

significance in immune-competent patients is unclear.

Multiple factors play a role in antibiotic selection for ABRS. S. pneumoniae may be associated with serious intracranial and extrasinus complications, and hence requires adequate coverage in initial therapy. Cover for $H$. influenzae (and M. catarrhalis in children) should be considered. Prior antibiotic use is a major risk factor for antibiotic-resistant strains. Because recent antibiotic exposure increases the risk of carriage and infection with resistant organisms, the choice and dosage of antibiotic therapy must take into account a history of recent antibiotic use. Other factors to consider are the severity of disease, its rate of progression, and varying rates of resistance in SA. Regarding whether antibiotics are necessary for ABRS, recent meta-analyses of antibiotics v. placebo showed only marginal benefit. ${ }^{[5]}$ Overall, 13 (95\% CI 9 - 22) adults require antibiotics to benefit one patient.

\subsection{Duration of antibiotic treatment for ABRS}

The duration of antibiotic treatment for ABRS is classically 10 days, based on published clinical trials in which pre- and post-treatment sinus aspirates were performed. However, evidence for moxifloxacin and telithromycin suggests that a shorter course of 5 - 7 days is clinically and/or bacteriologically equivalent to a 10 -day course. Recent adult studies also show that bacteriological eradication occurs within 72 hours with moxifloxacin (400 mg once daily) or with high-dose, short-course levofloxacin (750 mg once daily for 5 days). This higher dose of levofloxacin improves its $\mathrm{PK} / \mathrm{PD}$ profile, and in a comparative trial of this dose v. levofloxacin $500 \mathrm{mg}$ once daily for 10 days, clinical and microbiological efficacy was similar.

A recent meta-analysis examined the efficacy and safety of short $\mathrm{v}$. longer courses of antibiotic therapy for adults with ABRS in 12 randomised controlled trials (RCTs) ${ }^{[5]}$ No statistical difference in efficacy was noted between short-course ( 3 - 7 days) v. longcourse ( 6 - 10 days) antibiotic therapy (odds ratio (OR) $0.95 ; 95 \%$ CI $0.81-1.12$ ). In addition, no differences in microbiological efficacy (OR 1.30; 95\% CI 0.62 - 2.74), relapse rates (OR $0.95 ; 95 \%$ CI 0.63 - 1.37) or adverse effects (OR 0.88 ; 95\% CI 0.71 - 1.09) were found. However, if only the studies that compared 5 days (short course) v. 10 days (long course) were included (five RCTs), adverse effects were significantly fewer for short-course treatment (OR 0.79; 95\% CI 0.63 - 0.98). Data for children are inconclusive, however, as shorter courses of therapy have not been studied. The recommended duration of therapy for uncomplicated ABRS in adults is therefore 5 days.

\subsection{Failure to respond to antibiotics in ABRS}

For clinical failure (e.g. persistent fever) after 48 - 72 hours of appropriate, compliant antibiotic therapy, consider referral to an otorhinolaryngologist for further evaluation. A computed tomography scan, fibreoptic endoscopy or sinus aspiration and culture may be necessary. This is relevant in areas with high prevalence of antibiotic-resistant $S$. pneumoniae, as are most major urban centres in SA.

\subsection{Antibiotic recommendations for ABRS \\ 4.3.1 Children}

Antibiotic recommendations for children with AOM or ABRS are set out in Table 6.

\subsubsection{Adults}

Antibiotic recommendations for adults with ABRS or AOM are set out in Table 7.

\section{Beta-lactam allergy}

The high prevalence of penicillin nonsusceptibility and cross-resistance in $S$. pneumoniae has complicated the management of penicillin-allergic patients and limited the choice of alternative agents, particularly in children. Clinicians should differentiate an immediate type 1 IgE-mediated hypersensitivity reaction from other less dangerous types of hypersensitivity. Classic signs of type 1 hypersensitivity are anaphylaxis, angiooedema, urticarial rash and bronchospasm. If a type I hypersensitivity reaction to penicillin has occurred, all $\beta$-lactam antibiotics should be avoided unless there is no alternative drug available, when penicillin desensitisation can be attempted as an inpatient.

Patients with other types of hypersensitivity reactions, usually a maculopapular rash on amoxicillin, should avoid all penicillins but may tolerate other $\beta$-lactam antibiotics such as cephalosporins. The first-generation cephalosporins should be avoided as they have a higher risk of cross-reactivity with penicillin, but this risk is much lower for second- or thirdgeneration cephalosporins (reported to be only $0.1 \%)^{[27,28]}$

Consensus opinion suggests that if the previous reaction to penicillin was a maculopapular rash, it is relatively safe to use second- or third-generation cephalosporins, and use would depend on the patient's social circumstances and access to followup. However, in patients with a remote history of a rash on penicillin, it is often difficult to differentiate a maculopapular rash from an urticarial rash - all $\beta$-lactam antibiotics should be avoided if urticaria occurred on penicillins, as this is a type 1 reaction. In this setting, skin testing before using a cephalosporin is recommended, as a positive reaction to penicillin indicates type 1 hypersensitivity. ${ }^{[5]}$

In the latter patients, including children with a complicated and/or severe initial presentation and a history/confirmation of immediate type 1 hypersensitivity response to penicillin, levofloxacin is recommended 
as an alternative to amoxicillin-clavulanate or ceftriaxone. Owing to possible selection of resistance among pneumococci and other pathogens associated with widespread use, this is the only scenario in which levofloxacin in URTIs in children is recommended. Although levofloxacin's safety profile in children has been studied extensively, the incidence of musculoskeletal events (arthritis or arthralgia and tendinopathy) involving weight-bearing joints was increased in levofloxacin-treated children. ${ }^{[5,29-31]}$ Experience with moxifloxacin in children is relatively limited.

Endorsement. These recommendations are endorsed by the Infectious Diseases Society of Southern Africa, the Southern African Society for Paediatric Infectious Diseases and the Federation of Infectious Diseases Societies of Southern Africa.

Disclaimer. This statement is published for educational purposes only. The recommendations are based on currently available scientific evidence together with the consensus opinion of the authors. Adherence to these recommendations is voluntary and does not account for individual variation among patients; the recommendations are not intended to supplant physician judgement with respect to particular patients or special clinical situations. In addition, the recommendations do not indicate an exclusive diagnostic workup or course of treatment or serve as a standard of medical care.

Review panel. R Dagan (Professor of Paediatric and Infectious Diseases, Soroka University Medical Center and Faculty for Health Sciences, BenGurion University, Beer-Sheva, Israel), K P Klugman (Professor of Infectious Diseases, Department of Global Health, The Rollins School of Public Health, Emory University, Atlanta, USA), M Mendelson (Head of the Division of Infectious Diseases and HIV Medicine, Department of Medicine, University of Cape Town and Groote Schuur Hospital, Cape Town, South Africa).

Author disclosures. A J Brink: GlaxoSmithKline/Aspen speaker's bureau (SB); Sanofi Aventis SB, research grant (RG), research support (RS); MSD SB; Pfizer SB; M F Cotton: ViiV advisory board (AB); GlaxoSmithKline/Aspen RG; Gilead RG, Bristol-Myers Squibb grant investigator (GI); C Feldman: Abbott AB, SB; Astra-Zeneca SB; Sanofi Aventis SB; MSD AB SB; Pfizer AB SB; GlaxoSmithKline/Aspen AB, SB, Sandoz consultant (C); R L Friedman: Sanofi Aventis C, SB; GlaxoSmithKline/Aspen educational support (ES), SB; Takeda AB, ES; H Finlayson: none; R Green: AstraZeneca AB, ES, SB; Cipla AB, ES, SB; GlaxoSmithKline/Aspen, ES, SB; MSD AB, ES, SB; Mylan AB, ES, SB; Pfizer SB; Wyeth AB, ES, SB; H Hendson: none; M H Hockman: Sanofi Aventis AB, SB, ES; MSD AB, SB; Pfizer SB; Roche ES SB; GlaxoSmithKline/Aspen ES, SB, RS; Schering-Plough ES, SB; G Maartens: none; S A Madhi: Pfizer AB, GI, research contractor (RC), RG, SB; Sanofi Pasteur RC, SB; GlaxoSmithKline AB, GI, RC, RG, SB; Novartis RC, RG, AB; G Reubenson: Abbvie SB; Pfizer SB, ES; Sanofi Aventis research relationship (RR), ES; E J Silverbauer: none; I L Zietsman: GlaxoSmithKline/Aspen SB; Sanofi Aventis SB; MSD SB, ES; Pfizer ES. 1. Brink AJ, Cotton MF, Feldman C, et al. for the Working Group of the Infectious Diseases Society
of South Africa. Guideline for the management of upper respiratory tract infections. S Afr Med J 2004;94(6):475-483.
2. Brink AJ, Cotton MF, Feldman C, et al. for the Working Group of the Infectious Diseases Society of Southern Africa. Updated guideline for the management of upper respiratory tract infections in South Africa: 2008. S Afr J Epidemiol Infect 2008;23(4):27-40.

3. Jacobs MR. World trends in antimicrobial resistance among common respiratory tract pathogens in children. 3. Jacobs MR. World trends in antimicrobial resistance among common respiratory tract pathogens in
Pediatr Infect Dis J 2003;22(8):S109-S119. [http://dx.doi.org/10.1097/00006454-200303000-00005]

4. Hockman MH. The effect of Prevnar vaccination on otitis media in Gauteng, South Africa. Presented at the 4. Hockman MH. The effect of Prevnar vaccination on otitis media in Gauteng, South Africa. Presented at the
11th European Symposium on Paediatric Cochlear Implantation (ESPCI), Istanbul, Turkey, 18-21 May 2013.

11th European Symposium on Paediatric Cochlear Implantation (ESPCI), Istanbul, Turkey, 18-21 May 2013.
5. Chow AW, Benninger MS, Brook I, et al. IDSA Clinical practice guideline for acute bacterial rhinosinusitis 5. Chow AW, Benninger MS, Brook I, et al. IDSA Clinical practice guideline for acute bacterial rhinosinusitts
in children and adults. Clin Infect Dis 2012;54(8):1041-1045. [http://dx.doi.org/10.1093/cid/cir1043]

6. Van Driel ML, De Sutter AIM, Keber N, Habraken H, Christiaens T. Different antibiotic treatments for group A streptococcal pharyngitis. Cochrane Database Syst Rev 2013, Issue 4. Art. No.: CD004406. [http://dx.doi.org/10.1002/14651858.CD004406.pub3]

7. Lieberthal AS, Carroll AE, Chonmaitree T, et al. The diagnosis and management of acute otitis media. Pediatrics 2013;131(3):e964-e999. [http://dx.doi.org/10.1542/peds.2012-3488]

8. Pechere JC. Parameters important in short antibiotic courses. J Int Med Res 2000;28(Suppl 1):3A-12A.

9. Huebner RE, Wasas AD, Hockman M, Klugman KP, for the ENT Study Group. Bacterial aetiology of non-resolving otitis media in South African children. J Laryngol Otol 2003;117(3):169-172. [http:// dx.doi.org/10.1258/002221503321192430]

10. Zietsman IL, Brink AJ. National surveillance of private sector respiratory tract pathogens in South Africa, 2010. S Afr J Epidemiol Infect 2011;26(2):51-53.

11. Shulman ST, Bisno AL, Clegg HW, et al. Clinical practice guideline for the diagnosis and management of group A streptococcal pharyngitis: 2012 Update by the Infectious Diseases Society of America. Clin of group A streptococcal pharyngitis: 2012 Update by the Infectiou
Infect Dis 2012;55(10):1-17 [http://dx.doi.org/10.1093/cid/cis629]

12. Arguedas A, Mohs E. Prevention of rheumatic fever in Costa Rica. J Pediatr 1992;121(4):569-572. [http://dx.doi.org/10.1016/S0022-3476(05)81146-1]

13. Bass JW. A review of the rationale and advantages of various mixtures of benzathine penicillin G. Pediatrics 1996;97(6):960-963

14. Amir J, Ginat S, Cohen YH, Marcus TE, Keller N, Varsano I. Lidocaine as a diluent for administration of benzathine penicillin G. Pediatr Infect Dis J 1998;17(10):890-893. [http://dx.doi. org/10.1097/00006454-199810000-00008]

15. Dicuonzo G, Fiscarelli E, Gherardi G, et al. Erythromycin-resistant pharyngeal isolates of Streptococcus pyogenes recovered in Italy. Antimicrob Agents Chemother 2002;46(12):3987-3990. [http://dx.doi. org/10.1128/AAC.46.12.3987-3990.2002]

16. Reinert RR, Lutticken R, Bryskier A, Al-Lahham A. Macrolide-resistant Streptococcus pneumoniae and Streptococcus pyogenes in the pediatric population in Germany during 2000-2001. Antimicrob Agents Chemother 2003;47(2):489-493. [http://dx.doi.org/10.1128/AAC.47.2.489-493.2003]

17. Clegg HW, Ryan AG, Dallas SD, et al. Treatment of streptococcal pharyngitis with once-daily compared with twice-daily amoxicillin. Pediatr Infect Dis J 2006;25(9):761-767. [http://dx.doi.org/10.1097/01.
. inf.0000235678.46805.92]

18. Lennon DR, Farrell E, Martin DR, Stewart JM. Once-daily amoxicillin versus twice-daily penicillin V in group A $\beta$-haemolytic streptococcal pharyngitis. Arch Dis Child 2008;93(6):474-478. [http://dx.doi. org/10.1136/adc.2006.113506

19. Dohar J, Giles W, Roland P, et al. Topical ciprofloxacin/dexamethasone superior to oral amoxicillin/ clavulanic acid in acute otitis media with otorrhea through tympanostomy tubes. Pediatrics 2006;118(3):e561-e569. [http://dx.doi.org/10.1542/peds.2005-2033]

20. Craig WA, Andes D. Pharmacokinetics and pharmacodynamics of antibiotics in otitis media. Pediatr Infect Dis J 1996;15(3):255-259. [http://dx.doi.org/10.1097/00006454-199603000-00015]

21. Nicolau DP, Sutherland CA, Arguedas A, Dagan R, Pichichero ME. Pharmacokinetics of cefprozil in plasma and middle ear fluid in children undergoing treatment for acute otitis media. Pediatr Drugs 2007;9(2):119-123. [http://dx.doi.org/10.2165/00148581-200709020-00005]

22. Leibovitz E, Piglansky L, Raiz S, et al. Bacteriologic efficacy of a three-day intramuscular ceftriaxone regimen in nonresponsive acute otitis media. Pediatr Infect Dis J 1998;17(12):1126-1131. [http:// regimen in nonresponsive acute otitis media. Pe
dx.doi.org/10.1097/00006454-199812000-00005]

23. McGee L, Klugman KP, Wasas A, Capper T, Brink AJ and the Antibiotics Surveillance Forum of South Africa. Serotype $19 \mathrm{~F}$ multiresistant pneumococcal clone harboring two erythromycin resistance determinants [erm(B) and mef(A)] in South Africa. Antimicrob Agents Chemother 2001;45(5):15951598. [http://dx.doi.org/10.1128/AAC.45.5.1595-1598.2001]

24. Leiberman A, Leibovitz E, Piglansky L, et al. Bacteriologic and clinical efficacy of trimethoprimsulfamethoxazole for treatment of acute otitis media. Pediatr Infect Dis J 2001;20(3):260-264. [http:// dx.doi.org/10.1097/00006454-200103000-00009]

25. Ingvarsson L, Lundgren K. Penicillin treatment of acute otitis media in children: A study of the duration of treatment. Acta Otolaryngol 1982;94(3-4):283-287. [http://dx.doi.org/10.3109/00016488209128915] 26. Leibovitz E, Dagan R. Otitis media therapy and drug resistance. Infect Med 2001;18(4):263-270.

27. Pichichero NE. Use of selected cephalosporins in penicillin allergic patients: A paradigm shift. Diagn Microbiol Infect Dis 2007;57(Suppl 7):13s-18s. [http://dx.doi.org/10.1016/j.diagmicrobio.2006.12.004]

8. Joint task force on practice parameters; American Academy of Allergy, Asthma and Immunology: Amerce College of Alergy American College of Allergy, Asthma and Immunology; Joint Council of Allergy, Asthma and Immunology. Drug allergy: An updated practice parameter. Ann Allergy Asthma Immunol
2010;105(4):259-273. [http://dx.doi.org/10.1016/j.anai.2010.08.002]

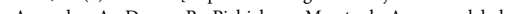

. Arguedas A, Dagan R, Pichichero M, et al. An open-label, double tympanocentesis study of levofloxacin therapy in children with, or at high risk for, recurrent or persistent acute otitis media. Pediatr Infect Dis J 2006;25(12):1102-1109. [http://dx.doi.org/10.1097/01.inf.0000202138.12950.3c] 0. Bradley JS, Jackson MA. The use of systemic and topical fluoroquinolones. Pediatrics 2011;128(4):e1034-1045. [http://dx.doi.org/10.1542/peds.2011-1496]

31. Noel GJ, Bradley JS, Kauffman RE, et al. Comparative safety profile of levofloxacin in 2523 children with a focus on four specific musculoskeletal disorders. Pediatr Infect Dis J 2007;26(10):879-891. [http://dx.doi.org/10.1097/INF.0b013e3180cbd382]

Accepted 2 February 2015 